\title{
Ocupação urbana em área de dunas no loteamento água das fontes no Município de São Gonçalo do Amarante/RN
}

\author{
Urban Occupation in Dune Area in the Water Plot of the Fontes in the Municipality of São \\ Gonçalo do Amarante/RN
}

\author{
GALVÃO ${ }^{1}$, S. P. M.; CARVALHO SEGUNDO ${ }^{2}$, E. L.; LIMA ${ }^{3}$, P. H. G.; BORGES FILHO ${ }^{4}$, R. D. \\ silvio_galvao@hotmail.com
}

\begin{abstract}
Resumo
Os Ecossistemas Dunares tem grande importância pela sua ampla diversidade. No município de São Gonçalo do Amarante/RN existe apenas uma pequena área de dunas, à nordeste, o qual a anos vem sofrendo intervenção antrópica. O presente trabalho busca analisar a ocupação urbana em área de dunas no município, no que diz respeito a abertura de uma rua no Loteamento Água das Fontes. Para tal, foram utilizados software SIG - Sistema de Informação Geográfica e visita In loco. A partir desta análise de viabilidade ambiental, foi possível identificar passíveis a vulnerabilidade ambiental para tal intervenção, em áreas de dunas e lagoas interdunares.
\end{abstract}

Palavras-chave: Dunas, Vulnerabilidade Ambiental, Ocupação Urbana

\begin{abstract}
The Dunares Ecosystems have great importance for their wide diversity. In the municipality of São Gonçalo do Amarante / RN there is only a small area of dunes, to the northeast, which for years has undergone anthropic intervention. The present work seeks to analyze the urban occupation in the area of dunes in the municipality, with regard to the opening of a street in the Water Plot of the Fontes. For this, GIS software - Geographic Information System and In loco visit were used. Based on this analysis of environmental feasibility, it was possible to identify the environmental vulnerability for such intervention in areas of dunes and interdunar lagoons.
\end{abstract}

Keywords: Dunes, Environmental Vulnerability, Urban Occupation,

\section{INTRODUÇÃO}

O crescimento urbano nas cidades brasileiras vem ocorrendo de forma acelerada e desordenada, onde a paisagem natural sofre constantes agressões ambientais, provocando um grande impacto e uma grande pressão em seus componentes naturais, sem que haja, na maioria das vezes, uma ação governamental efetiva que proporcione melhores condições de qualidade de vida para população.

Essa realidade não é diferente no município de São Gonçalo do Amarante, estado do Rio Grande do Norte. A ocupação urbana acabou se expandindo por áreas de preservação ambiental, como região de dunas, que é o caso deste trabalho. O município possui apenas uma pequena região de dunas e pela constante especulação da terra, provocando desmatamento, aterramento e abertura de trilhas, entre outros impactos.

\footnotetext{
${ }^{1}$ Sílvio Petronilo de Medeiros Galvão, Tecnólogo Ambiental, Secretaria Municipal de Meio Ambiente e Urbanismo, São Gonçalo do Amarante-RN, Brasil.

${ }^{2}$ Espedito Lima de Carvalho Segundo, Biólogo, Secretaria Municipal de Meio Ambiente e Urbanismo, São Gonçalo do Amarante-RN, Brasil.

${ }^{3}$ Pedro Henrique Godeiro de Lima, Geógrafo, Secretaria Municipal de Meio Ambienta e Urbanismo, São Gonçalo do Amarante-RN, Brasil.

${ }^{4}$ Ridon Dantas Borges Filho, graduando em Engenharia Ambiental e Sanitária (Unp), Secretaria Municipal de Meio Ambienta e Urbanismo, São Gonçalo do Amarante-RN, Brasil.
} 
No que se trata do homem e suas relações com a natureza, é necessário falar de geografia, mais precisamente, em um dos ramos da ciência geográfica, a biogeografia. Esta que estuda a distribuição em escala de tempo e espaço dos seres vivos na superficies da Terra. Com isso, podemos levar em conta as condições geográficas e a ação antrópica que determinam e influenciam nessa distribuição (SANTOS \& CARVALHO, 2012).

Segundo Santos \& Carvalho, a biogeografia:

(...) faz um estudo dos seres vivos, analisando sua participação e relação com o espaço geográfico (biosfera), tendo como objetivo compreender o papel dos seres vivos na organização do espaço geográfico e a influência dos mesmos na transformação da biosfera. Brown (2006) destaca que, "a Biogeografia é a ciência que se preocupa em documentar e compreender modelos espaciais de biodiversidade, estudando a distribuição dos organismos no passado e no presente" (SANTOS \& CARVALHO, 2012, p.: 3).

A região, geomorfologicamente é caracterizada como "Campo de Dunas com vegetação de restinga formando as dunas fixas" de constituição de areias quartzosas, imobilizadas sob a cobertura vegetal. O econssistema restinga estão localizados ao longo da costa brasileira formados principalmente em solos de areia quartzosas.

Em função das condições ambientais estabelecidas, diferentes tipos de vegetação podem ser reconhecidas e são denominados "fisionomias de Restinga". Com o objetivo de padronizar a nomenclatura e identificar as características principais das diferentes fisionomias encontradas na Restinga, existem resoluções que definem essas fisionomias.

Segundo a Resolução CONAMA n ${ }^{\circ}$ 303, a restinga é um depósito arenoso paralelo a linha da costa, de forma geralmente alongada, produzido por processos de sedimentação.

Entende-se por restinga um conjunto de ecossistemas que compreende comunidades vegetais florísticas e fisionomicamente distintas, situadas em terrenos predominantemente arenosos, de origens marinha, fluvial, lagunar, eólica ou combinações destas, de idade quaternária, em geral com solos pouco desenvolvidos (Brasil, 1999).

A vegetação de restinga da área de estudo compreende por formações arbustivas e arbóreas. Essa vegetação do ecossistema de restinga, são da frágeis e exerce papel fundamental para a estabilização dos sedimentos e a manutenção da drenagem natural, bem como para a preservação da fauna residente e migratória.

Nas restingas, são caracterizadas por vegetações do tipo arbustiva e arbórea. A arbustiva, como o nome já diz, é constituída por plantas arbustivas que apresentam características com espécies com cerca de 1 (um) metro a 5 (cinco) m de altura, com possibilidade de ocorrência de 
estratificação, epífitas, trepadeiras e acumulo de serapilheira. Nesse tipo de vegetação os arbustos podem formar moitas separadas por áreas com solo arenoso exposto. $\mathrm{Na}$ arbórea, a vegetação é densa com fisionomia arbórea, estratos arbustivos e herbáceos geralmente desenvolvidos e acúmulo de serapilheira, comportando também epífitos e trepadeiras. Na área de estudo em questão, são encontrados os dois tipos de vegetação da restinga.

Este artigo tem como objeto à análise da ocupação urbana em área de dunas, no que diz respeito a abertura de uma rua, no município de São Gonçalo do Amarante, estado do Rio Grande do Norte (RN), Brasil. Mais precisamente no Loteamento Água das Fontes, no bairro Jardins. A partir desta análise de viabilidade ambiental, foi possível identificar passíveis a vulnerabilidade ambiental para tal intervenção, em áreas de dunas e lagoas interduna1res. Com isso, para alcançar tal finalidade, foi preciso analisar os principais aspectos relacionados ao uso e ocupação do solo na área; caracterizar o quadro natural da área de estudo quanto aos elementos: geológicos, geomorfológicos e biótico; identificar áreas de restrição ambiental (considerando a legislação vigente) e/ou ambientalmente sensíveis, dentro da área de influência direta.

A área de estudo está localizado no Bairro Jardins, Loteamento Água das Fontes, na região Nordeste do município de São Gonçalo do Amarante/RN. O principal acesso ao local se dá pela rodovia BR-101 e estradas internas sem pavimentação do loteamento. A figura 1 abaixo temos o mapa de localização da área do empreendimento, partindo como ponto de referência o centro do Município de São Gonçalo do Amarante.

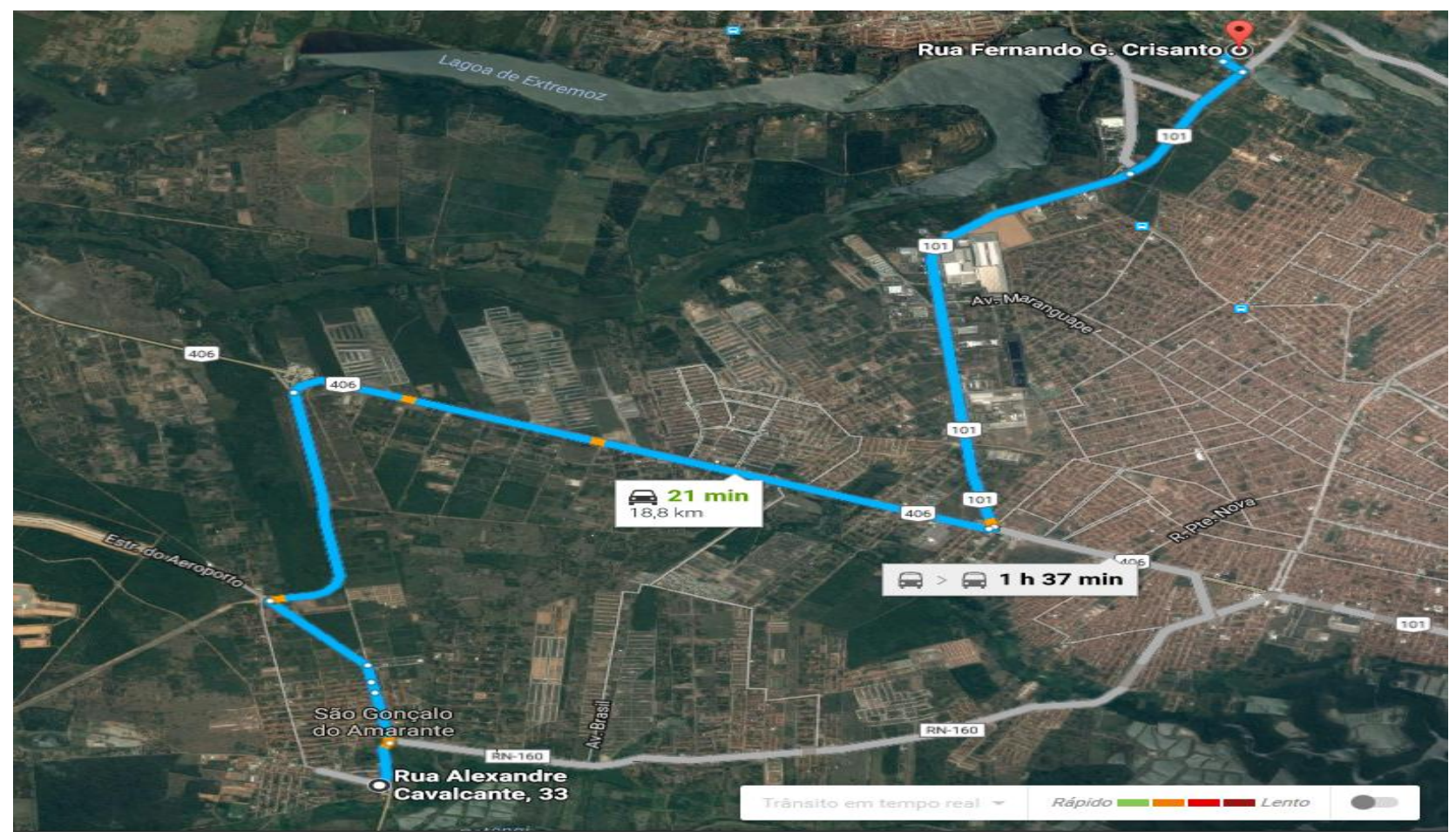

Figura 1: Localização e acesso a Rua Projetada. Fonte: Google Maps. 
A área está localizada a aproximadamente $18 \mathrm{~km}$ com acesso através da via metropolitana e BR-101. Em linha reta a rua está a uma distância de aproximadamente $11 \mathrm{~km}$ do centro do município. $\mathrm{O}$ acesso a área é bastante facilitado.

\section{METODOLOGIA}

A metodologia do trabalho consistiu na revisão bibliográfica, com leitura de livros, artigos científicos e documentos oficiais do assunto abordado.

Após essa revisão, foi realizada a visita in loco, procedimento fundamental para o reconhecimento da área. Durante a visita, foi possível fotografar pontos da área de estudo e os arredores e foi de suma importância para identificação de solo, geomorfologia, espécies de plantas da área e atividades antrópicas.

Com essas informações organizadas, foi possível elaborar mapas referentes à localização do bairro, identificando principalmente a área de estudo, o zoneamento geomorfológico e ambiental. O mapeamento, bem como o layout final do mapa de localização foi elaborado pelo Google Earth Pro e os demais mapas por meio de um software SIG - Sistema de Informação Geográfica, no caso, a versão 10.3 do ArcGIS (ESRI @).

\section{RESULTADOS E DISCUSSÃO}

O loteamento Águas das Fontes, está inserido na Zona de Expansão Urbana - ZEU do município de São Gonçalo do Amarante de acordo com o Plano Diretor.

A área em questão é caracterizada geomorfologicamente como "Campo de Dunas com vegetação de restinga formando as dunas fixas" de constituição de areias quartzosas, imobilizadas sob a cobertura vegetal. Os corredores interdunares proporcionam o surgimento de reservatórios de água doce, sobretudo para a recarga dos aquíferos, uma vez que as águas pluviais que penetram no solo acumulam-se facilmente. Essas feições possuem uma porosidade e permeabilidade alta, o que permite os usos dessas áreas como reservatórios naturais de recursos hídricos para a manutenção do meio natural e demais necessidades da população; entretanto, esse tipo de solo torna-as extremamente frágil em áreas de adensamento urbano ou em áreas com ocupação irregular como no caso do loteamento em questão. 


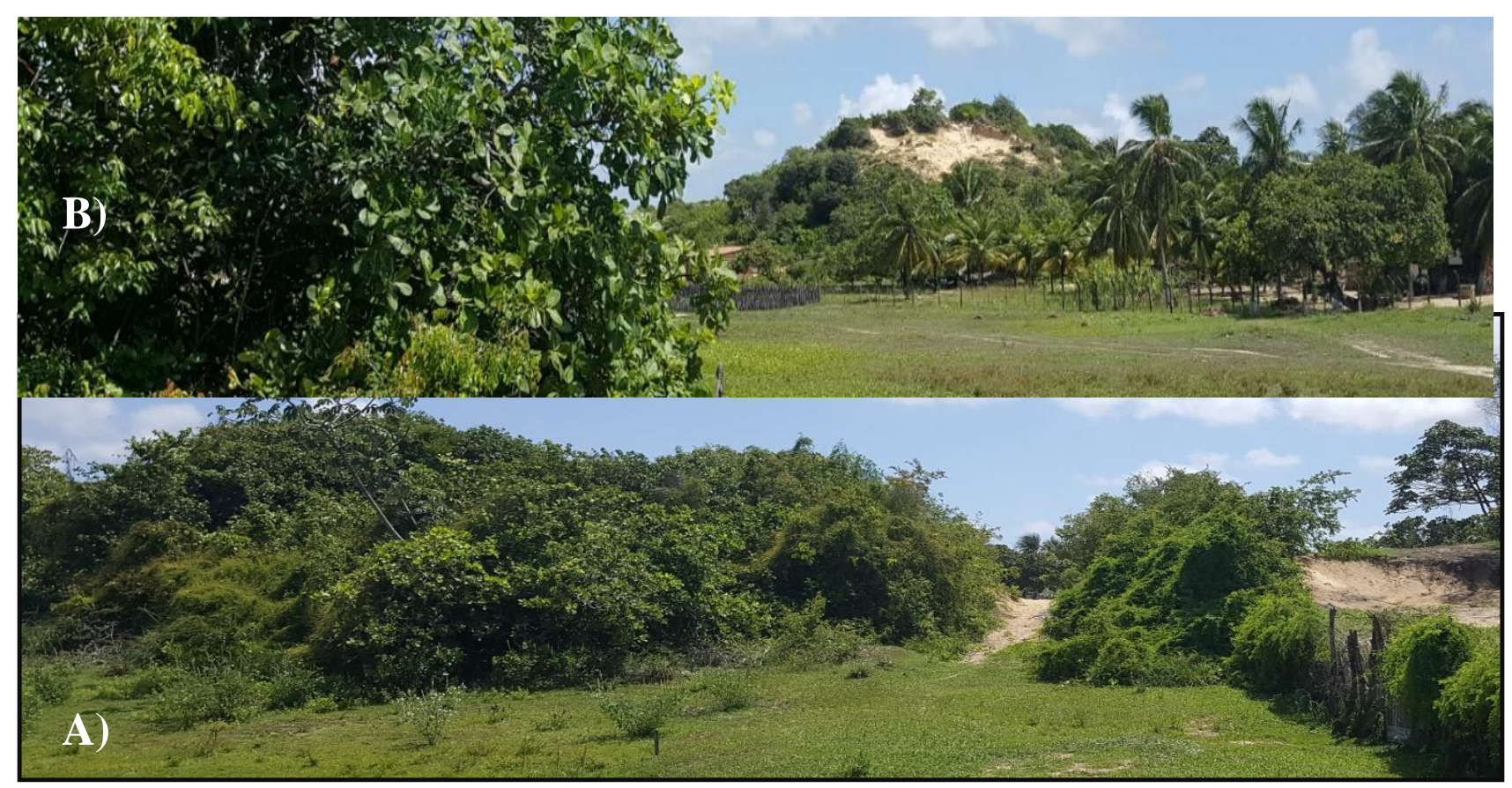

Figura 2: Área solicitada para abertura da Rua Projetada. A) Duna vegetada localizada na área solicitada para abertura de Rua; B) Duna fixa localizada a $100 \mathrm{~m}$ da área solicitada para abertura da Rua. Fonte: SEMURB, 2017.

Segundo a Resolução CONAMA n 303 , a restinga é um depósito arenoso paralelo a linha da costa, de forma geralmente alongada, produzido por processos de sedimentação. A cobertura vegetal nas restingas ocorrem mosaico, e encontra-se em praias, cordões arenosos, dunas e depressões, apresentando, de acordo com o estágio sucessional, estrato herbáceo, arbustivos e arbóreo, este último mais interiorizado, a seguir temos o zoneamento Geomorfológico da área. 


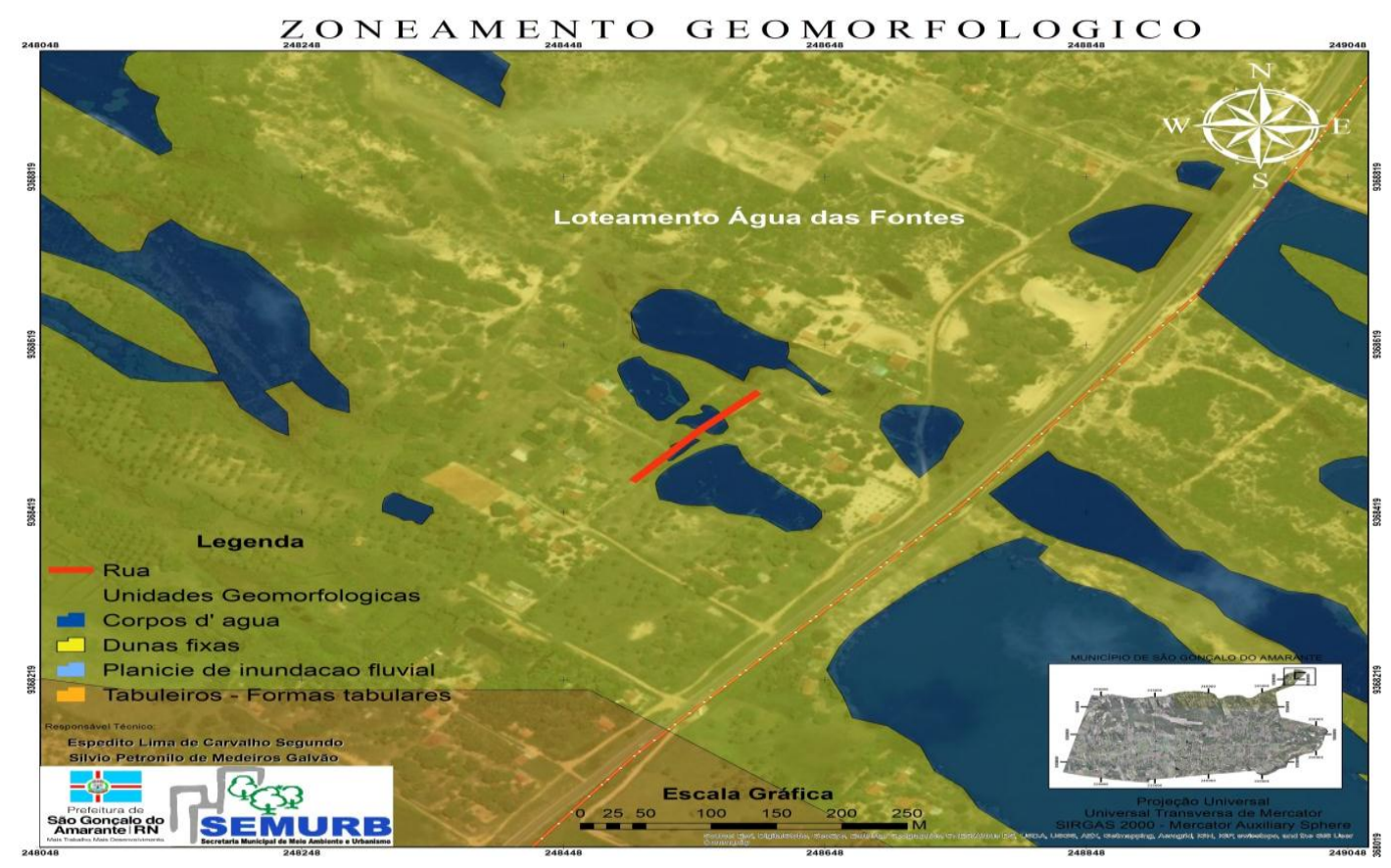

Figura 3: Geomorfologia da área. Fonte: SEMURB, 2017.

Através do mapeamento anterior foi possível constatar que a área destinada ao projeto da rua (sinalizada por uma linha vermelha) está localizada em área de dunas fixas a qual se for implantada irá cortar duas lagoas interdunares.

No mapeamento realizado foi possível identificar um mosaico composto por várias feições como: vegetação de restinga, dunas fixas, lagoas interdunares, vias de acessos internos, plantações, edificações, áreas antropizadas etc. Apesar da área está localizada em uma Zona de Expansão Urbana - ZEU, a mesma possui características rurais, onde as propriedades podem ser enquadradas como minifúndios onde desenvolve-se atividades produtivas como: Agricultura, horticultura, psicultura, pequenas criações de suínos e gado e até matadouro ilegal.

O estrato da vegetação encontrada na duna a qual foi solicitada a abertura de Rua é do tipo herbácea/Arbustiva com altura variando entre 1 e $3 \mathrm{~m}$ de altura. As epífitas ocorrem no estrato arbustivo, são elas: bromélias, fungos, líquens, musgos etc.

A cobertura vegetal do corpo dunar é composta por espécies de fitofisionomia de ecossistema de Mata Atlântica - a vegetação é do tipo Restinga que cresce sobre a área dunar, dentre as várias espécies que compõem essa vegetação destacam-se: cajueiros (Anarcadium occidentale), Mangabeira (Hancornia speciosa), pitanga da restinga de cachorro (Neomitranthes obscura). A seguir, temos algumas fotos das espécies que foram identificadas no fragmento de duna em estudo. 

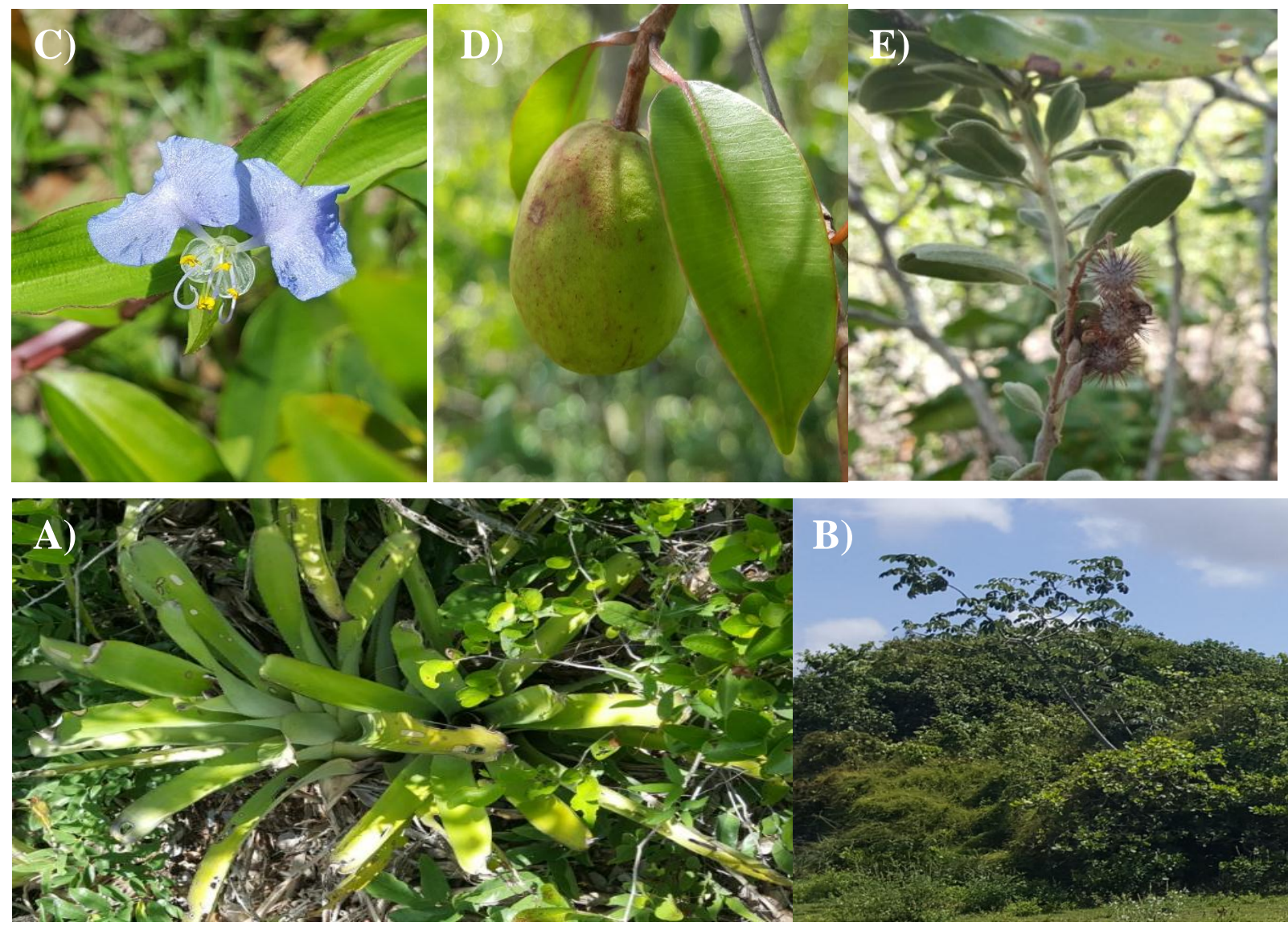

Figura 4: Espécimes vegetais identificadas na área. A) Hohenbergia ramageana, B) Cecropuia pachystachya e Anacardium occidentale, C) Commelina erecta L., D) Hancornia speciosa, E) Krameria Tomentosa A. Fonte: SEMURB, 2017.

$\mathrm{Na}$ área de estudo, o qual foi solicitado a abertura da Rua no fragmento dunar, foram identificadas 17 espécies vegetais diferentes. Abaixo, foram listados todas as espécies de vegetais que foram encontrados na área (tabela 1).

Tabela 1: Relação das espécies vegetais identificadas na Duna. Fonte: SEMURB, 2017.

\begin{tabular}{|c|c|c|}
\hline Família & Nome Cientfico & Nome Popular \\
\hline Fabaceae & Crotalaria retusa $L$. & \\
\hline Fabaceae & Centrosema brasilianum & \\
\hline Fabaceae & $\begin{array}{c}\text { Chamaecrista } \\
\text { rotundifoliavar. grandiflora }\end{array}$ & \\
\hline Convolvulaceae & Ipomoea Alba L. & \\
\hline Convolvulaceae & Commelina erecta $L$. & Erva de Santa Luzia \\
\hline Cecropiaceae & $\begin{array}{c}\text { Cecropuia pachystachya } \\
\text { trécul }\end{array}$ & Embaúba \\
\hline Cyperaceae & Pycreus polystachyos & Ciperus \\
\hline Poaceae & $\begin{array}{l}\text { Panicum dichotomiflorum } \\
\text { Michx. }\end{array}$ & Capim \\
\hline
\end{tabular}




\begin{tabular}{|ccc|}
\hline Rubiaceae & $\begin{array}{c}\text { Richardia brasiliensis } \\
\text { Gomes }\end{array}$ \\
\hline Anacardiaceae & Anacardium occidentale & Cajueiro \\
\hline Krameriaceae & Krameria Tomentosa A. & Carrapicho de Ovelha \\
\hline Apocynaceae & Hancornia speciosa & Mangabeira \\
\hline Bromeliaceae & Hohenbergia ramageana & Bromélia \\
\hline Myrtaceae & Eugenia uniflora L. & Pitanga \\
\hline Myrtaceae & Neomitranthes obscura & Pitanga da Restinga de \\
\hline Myrtaceae & Cachorro \\
\hline Arecacea & Anthurium affine & Antúrio \\
\hline
\end{tabular}

A área possui uma ampla diversidade e importância ecológica, mesmo sofrendo intensas ações antrópicas através da implantação do loteamento e sua ocupação, as quais contribuíram para degradação dos corpos dunares, com a perda da vegetação e consequentemente, a aceleração de processos erosivos, terraplenagem da área e extração irregular de areia, o que vem descaracterizando a paisagem natural.

Durante visita realizada in loco no dia 25 de janeiro de 2017 foi observado a presença de lagoas e corredores interdunares com a vegetação nativa de restinga.

A área em questão sofreu bastante intervenção antrópica, perdendo grande parte de suas características naturais, devido a ocupação humana e atividades desenvolvidas na área, como: Criação de animais, áreas de pastagem, agricultura de subsistência, piscicultura, matadouros, dentre outras.

A Lei 12.651 de 2012 despreza a proteção das dunas e repete o que era definido no antigo Código Florestal, em seu Artigo $4^{\circ}$, inciso VI caracterizando como Área de Preservação Permanente - APP somente as restingas, como fixadoras de dunas ou estabilizadoras de mangues, em resumo considera como APP somente a vegetação que recobre a duna. Tal lei delimita as Áreas de Preservação Permanente de acordo com sua classificação, segue a baixo parte da minuta da lei onde enquadra APP para Lagos e restingas fixadoras de dunas. Segundo o Novo Código Florestal, Lei n 12.651, Art. 4, Inciso II e VI:

Art. $4^{\underline{0}}$ Considera-se Área de Preservação Permanente, em zonas rurais ou urbanas, para os efeitos desta Lei:

II - as áreas no entorno dos lagos e lagoas naturais, em faixa com largura mínima de:

a) 100 (cem) metros, em zonas rurais, exceto para o corpo d'água com até 20 (vinte) hectares de superfície, cuja faixa marginal será de 50 (cinquenta) metros;

$V I$ - as restingas, como fixadoras de dunas ou estabilizadoras de mangues; 
Para identificação das APP foi realizada uma análise espacial em uma carta com escala de $1: 1.250$, escala essa que fora a mais adequada pra o trabalho realizado e identificação em tela dos componentes os quais estão inseridos no mosaico estudado. Foram utilizadas as linhas vetorizadas das lagoas e lagos do Banco de Dados do IDEMA/2006 os quais foram retificados, e a partir delas gerado um buffer com a distância de 50 metros determinada pelo Art. 4 inciso II paragrafo a), da Lei 12.651 .

Assim, foi possível observar que a área a qual pretende-se realizar a abertura de rua é equivalente a aproximadamente $240 \mathrm{~m}^{2}$, que além de ser enquadrada como área de restinga a qual recobre uma duna, também é enquadrada como uma área de APP de 50m da lagoa a qual esta localizada a Sul da área objeto de estudo, abaixo segue o mapeamento realizado.

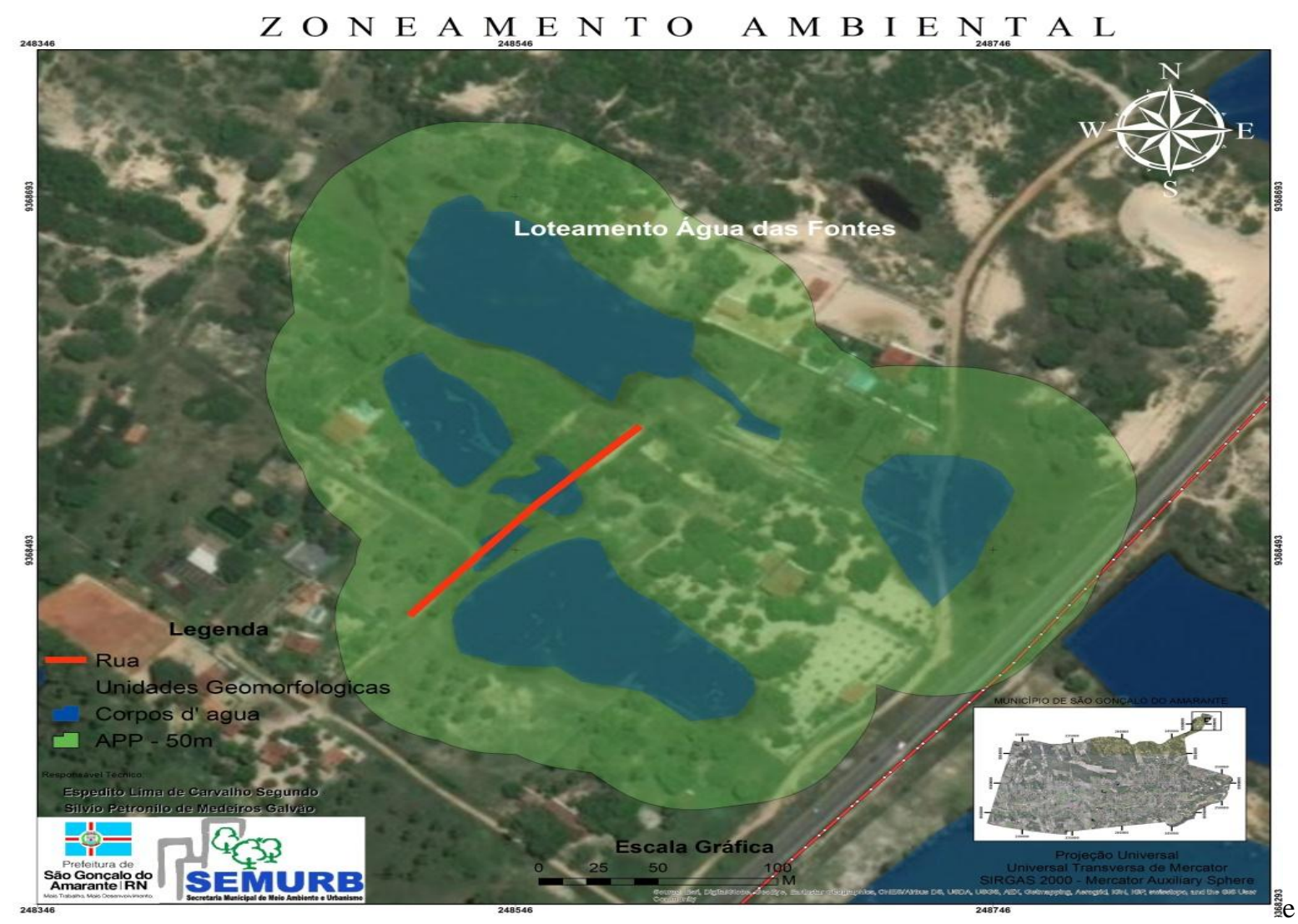

Figura 5: identificação de áreas de APP acordo com a Lei 12.651/12. Fonte: SEMURB/2017.

Como esta região está em constante crescimento, é necessário disciplinar o uso do solo, evitando edificações em lugares irregulares, tráfego de veículos, alterações no fluxo natural de água pluvial, alteração e/ou barramento dessas lagoas interdunares. É preciso estabelecer faixas de recuo, e impedir que se construam obras e possível aterramento da lagoa e destruição da duna e sua vegetação. Durante o mapeamento foi possível observar em tela vários empreendimentos dentro das 
áreas de APP, onde o loteamento foi parcelado de forma irregular, não respeitando as diretrizes ambientais.

Ainda segundo a Resolução no 303 do Conselho Nacional do Meio Ambiente - CONAMA, as dunas cobertas ou não por vegetação nativa de acordo com o Artigo $3^{\circ}$, inciso XI são consideradas como APP. A proteção integral das dunas, vegetadas ou não, estabelecida por está resolução permanece, somente sendo possível a intervenção nestes ecossistemas nos termos da Resolução CONAMA 369/06.

\section{CONSIDERAÇÕES FINAIS}

A área de estudo possui uma ampla diversidade e importância ecológica. Com a implantação do loteamento e sua ocupação em área de dunas, contribuíram para degradação dos corpos dunares, com a perda da vegetação e consequentemente, a aceleração de processos erosivos, terraplenagem da área e extração irregular de areia, o que vem descaracterizando a paisagem natural.

Dessa forma, a implantação de uma estrada projetada no local em questão se classifica como inadequada, pois na área possui predominantemente coberturas de alteração arenosas com cobertura de vegetação nativa e com o lençol freático mais superficial, ocorrendo periodicamente a formação de lagoas temporárias, sendo classificadas como Área de Preservação permanente - APP.

Espera-se ainda, que esse estudo sirva como base para a regularização do empreendimento, respeitando os limites da APP, com intuito de compatibilizar o tipo de uso do solo na localidade e respeitar as restrições impostas pelas características da área.

\section{REFERÊNCIAS}

AZEVEDO, N.H.; MARTINI, A.M.Z.; OLIVEIRA, A.A.; SCARPA, D.L.; PETROBRAS:USP, IB, LabTrop/BioIn (org.). Ecologia na restinga: uma sequência didática argumentativa. 1ed. São Paulo: Edição dos autores, Janeiro de 2014. 140p.

BRASIL. Conselho Nacional do Meio Ambiente. Resolução 303, de 20 de março de 2002. Dispõe sobre os parâmetros, definições e limites de Áreas de Preservação Permanente de reservatórios artificiais e o regime de uso do entorno. Diário Oficial da União, Brasília, 13 mai. 2002.

BRASIL. Lei $n^{\circ}$ 12.651, de 25 de maio de 2012. Dispõe sobre a proteção da vegetação nativa; altera as Leis nos 6.938, de 31 de agosto de 1981, 9.393, de 19 de dezembro de 1996, e 11.428, de 22 de dezembro de 2006; revoga as Leis nos 4.771, de 15 de setembro de 1965, e 7.754, de 14 de abril de 1989, e a Medida Provisória no 2.166-67, de 24 de agosto de 2001; e dá outras providências. 
CESTARO, L. A.. Fragmentos de florestas atlânticas no Rio Grande do Norte: relações estruturais, florísticas e fitogeográficas. Tese (Doutorado em Ecologia e Recursos Naturais) Centro de Ciências Biológicas e da Saúde, Universidade Federal de São Carlos, São Carlos, 2002.

. Lei Complementar n 049 de 2009: institui o Plano de Diretor do Município de São Gonçalo do Amarante/RN.

FRANCO, E. Biogeografia do Estado de Sergipe. Imprensa: Aracaju/SE, Segrase, 1983. 139 p.

GOMES, L. J.; SANTANA, V.; RIBEIRO, G. T. Unidades de Conservação no Estado de Sergipe. Revista da Fapese, v. 2, n. 1, p. 101-112, jan./jun. 2006. Disponível em: <http://www.fapese.org.br> Acesso em 20/09/2007.

INSTITUTO AMBIENTAL DO PARANÁ \& DEUTSCHE GESELLSCHAFT FÜR TECHNISCHE ZUSAMMENARBEIT (IAP \& GTZ). Manual de avaliação de impactos ambientais, 1993, $2^{\mathrm{a}}$ edição.

IDEMA - Instituto de Desenvolvimento Econômico e Meio Ambiente do Rio Grande do Norte. Perfil do seu município - São Gonçalo do Amarante/RN 2014.

MESQUITA, T.P.N.; DINIZ, R.F. Ocupação Antrópica em Área de Dunas no Município de NatalRN: Algumas Questões Ambientais e Legais. VI Simpósio Nacional de Geomorfologia / Regional Conference on Geomorfology, Ano 2006. Cidade: Goiânia - GO. 2006.

NUNES, Elias. O Meio Ambiente da Grande Natal. 2 ed. rev. atual. e ampl. Natal: Elias Nunes, 2009, 188 p.

SANTOS, C. de Resende; CARVALHO, Márcia Eliane Silva. A Contribuição da Biogeografia na Formação do Geógrafo: Os Desafios de Ensinar e Aprender Geografia Física e Educação Ambiental. REVISTA GEONORTE, Edição Especial, V.3, N.4, p. 1-11, 2012.

SANTOS, Maria da Conceição Nasser dos FILGUEIRA, Maria de Fátima; COSTA, Morgana Jales da. Análise das condições ambientais das dunas ao Sul de Natal/RN, em função do uso e ocupação do solo. 1992. Trabalho de conclusão de curso (graduação)- Universidade Federal do Rio Grande do Norte, Natal, 1992.

SILVA, Elisangela Alves de Jesus. As Dunas eólicas de Natal-RN: Datação e Evolução. 2003, 112f. Dissertação de Mestrado, 2003. Universidade Federal do Rio Grande do Norte, Natal, 2003.

SOUZA, Bernadete de Lourdes Queiroga de. Mudanças ambientais no entorno do prolongamento da avenida Prudente de Morais: quadrilátero dunar do San Vale, Natal-RN.1999. Trabalho de conclusão de curso (Especialização). Universidade Federal do Rio Grande do Norte, Natal, 1999. 


\section{AGRADECIMENTOS}

A elaboração deste trabalho não teria sido possível sem a colaboração, estímulo e empenho de diversas pessoas.

Ao Secretário de Meio Ambiente e Urbanismo do município de São Gonçalo do Amarante, Paulo de Tarso Dantas Lima e também a equipe do setor de Meio Ambiente.

Agradecemos também, ao Doutor Diógenes Félix da Silva Costa, professor do Departamento de Geografia da Universidade Federal do Rio Grande do Norte - Campus de Caicó, pelas orientações para esta pesquisa.

Recebido em: 15/08/2018

Aceite para publicação em: 05/11/2018 